\section{Cloning human stem cells}

Pluripotent human embryonic stem cells have a unique ability to differentiate into any cell line. Although this has raised hopes that transplantation of stem cells may halt or reverse degenerative disorders such as diabetes and Parkinson's disease, the development of clinical applications has been slow because of the paucity of human stem cells available for research. Hwang and colleagues report a remarkable feat: the first \pm successful attempt at creating an + embryonic stem cell line from cloned human cells.

Their technique involved in transferring the nucleus of a so$\stackrel{0}{\circ}$ matic cell (with diploid chromo$\because$ somes) into an enucleated $\stackrel{\circ}{\circ}$ oocyte. An important underly- ing premise with this technique is that, once exposed to the oocyte's cytoplasm, the somatic genes will shut off and the embryonic genes will be activated. The therapeutic advantage of transplanting these cells back into the same patient is immense: the risk of immune rejection is eliminated.

A key to the success of this group was the abundant number of eggs they obtained for their experiments. Rather than obtaining unwanted eggs from infertility clinics, the authors recruited 16 women to undergo ovarian hyperstimulation to produce oocytes for the sole purpose of research; a total of 242 were obtained. The scientists were thus afforded the luxury of fine-tuning a number of steps in the cloning process. Rather than

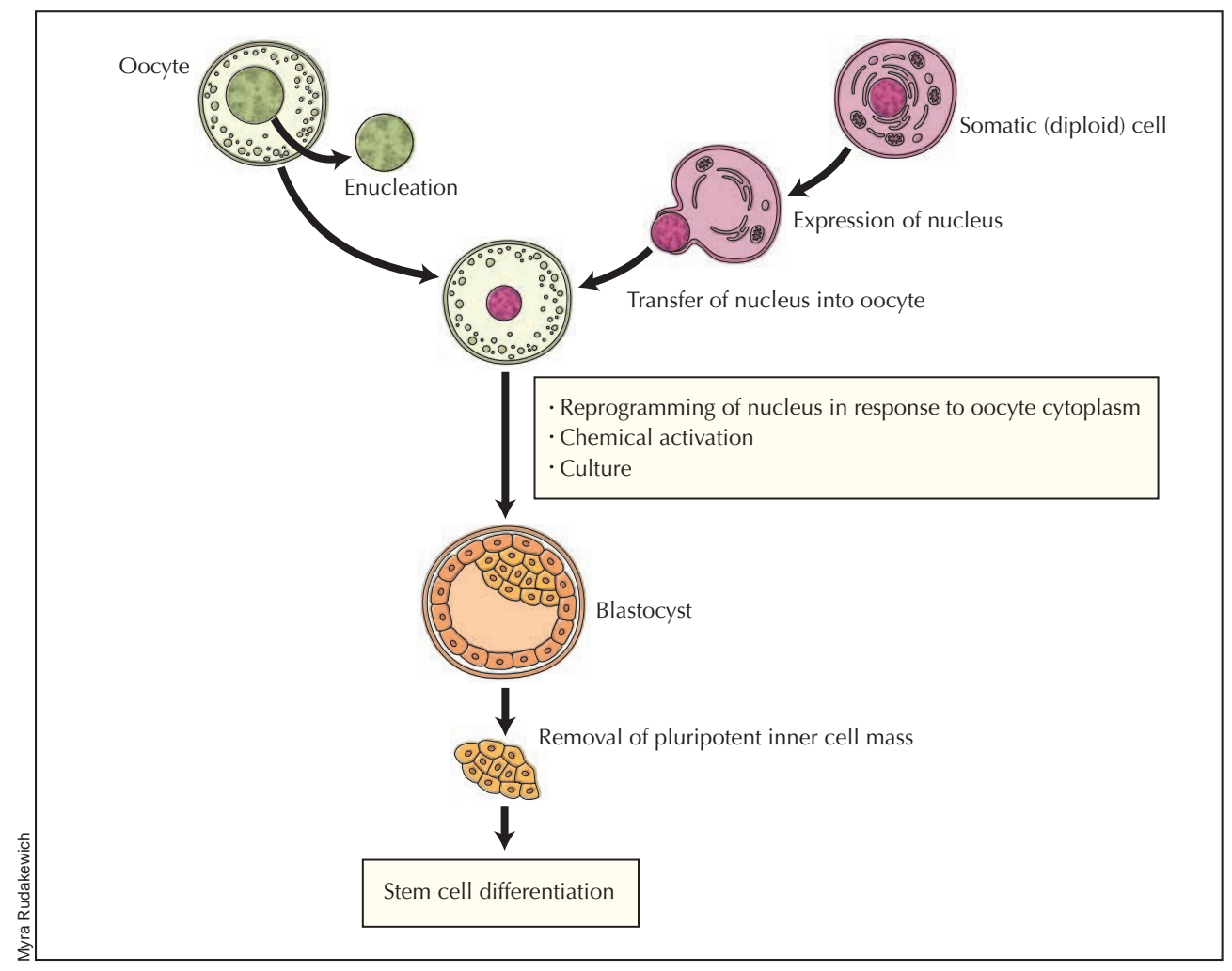

sucking out the nucleus from somatic cells with a pipette, they carefully squeezed them out, limiting damage to the precious genetic material. They ascertained that 2 hours was enough time to allow the transferred nucleus to adjust to its new surroundings and "reprogram" itself, and they determined a recipe for the right chemical soup to cause oocyte activation in the absence of sperm-mediated activation. Finally, they established a culture medium that allowed the cells to reproduce, substituting glucose for fructose in the brew.

To test for the ability of the cell line to differentiate, the scientists cultured the stem cells in a medium defined for neural cell differentiation; indeed, markers of neuroectoderm differentiation were detected. They also confirmed differentiation of stem cells into neuroepithelium, retinal epithelium, smooth muscle, bone, cartilage, connective tissues and glandular epithelium.

An important limitation to their findings lay in the fact that the oocyte may have developed on its own in a process called parthenogenesis. Although parthenogenesis is not known to occur in humans, and markers of a diploid cell were confirmed in the cell line, the authors openly state that they cannot entirely exclude this possibility.

Nevertheless, the findings of this study have enormous scientific and ethical repercussions: although the clinical applications for stem cell transplantation may be closer, so too may be the ability to clone a human being. (Hwang et al. Science Express Reports, 12 Feb 2004 [DOI: 10.1126/science.1094515] www . sciencemag.org )

$$
\text { - Stephen Choi, CMAJ }
$$

